\title{
MUSIK KOPLO SEBAGAI IDENTITAS KELOKALAN BARU PADA PENGGUNAAN BAHASA OSING BANYUWANGI (BERDASARKAN TINJAUAN SOSIO KULTURAL-HISTORIS)
}

\section{KOPLO MUSIC AS A NEW LOCAL IDENTITY IN THE USE OF \\ BANYUWANGI OSING (BASED ON CULTURAL-HISTORICAL SOCIAL REVIEW)}

\author{
Samudra Eka Cipta \\ Program Sarjana Departemen Pendidikan Sejarah \\ Fakultas Pendidikan Ilmu Pengetahuan Sosial \\ Universitas Pendidikan Indonesia \\ Email: samudra.eka@student.upi.edu
}

\begin{abstract}
ABSTRAK
Penelitian ini berusaha untuk mengkaji bagaimana fenomena musik koplo yang saat ini sudah menjadi trend dikalangan masyarakat luas termasuk kalangan anak muda. Penggunaan bahasa daerah menambah warna baru dalam upaya untuk melestarikan budaya lokal bahasa pada musik koplo. Di Banyuwangi yang mayoritas masyarakatnya berbahasa Osing menjadikan musik koplo sebagai salah satu langkah dalam memperkenalkan Budaya Osing. Para musisi Banyuwangi seperti Demy seorang penyanyi lokal Banyuwangi yang mempopulerkan Bahasa Using melalui judul lagu 'Kanggo Riko'. Bukan hanya saja musisi lokal akan tetapi musisi ternama sekalipun seperti Nella Kharisma juga mempopulerkan lagu yang berjudul 'Welas Hang Ring Kene \& Ngelabur Langit'. Bahkan musisi senior asal Catur Arum sudah terlebih dahulu memperkenalkan budaya Osing melalui lagu-lagu yang diciptakan. Dari peran para musisi tersebut dapat disimpulkan bahwa pengunaan bahasa Using dapat terus dilestarikan melalui musik di era serba digital. Pada penelitian ini terdapat beberapa rumusan masalah yakni: 1) bagaimana perkembangan awal Bahasa Osing?, 2) bagaimana awal perkembangan Musik Koplo, 3) bagaimana perkembangan Bahasa Osing hingga pada akhirnya menuju eksistensi pada kesenian Musik Koplo?
\end{abstract}

Kata Kunci: Bahasa, Osing, Banyuwangi, Jawa

\section{ABSTRACT}

This research seeks to examine how the Koplo music phenomenon that has become a trend among the wider community including young people. The use of regional languages adds new colors in an effort to preserve the local culture of language on music Koplo. In Banyuwangi, the majority of the society in Osing language makes the music Koplo as one of the steps in introducing the Osing culture. The musicians of Banyuwangi such as Demy a local singer Banyuwangi who popularized Using language through the title song ' 'Kanggo Riko ' '. It is not only a local musician but even famous musicians such as Nella Kharisma also popularized the song titled' 'Welas Hang Ring Kene \& Ngelabur Langit ' '. Even the senior musician from Catur Arum has first introduced the Osing culture through the songs that were created. From the role of the musicians it can be concluded that Using use 
P-ISSN 2580 - 7781

E-ISSN $2615-3238$

language can continue to be preserved through music in an all-digital era. In this study there are several problems in the problem namely: 1) How the early development of the Osing language?, 2) How the beginning of the development of Music Koplo, 3) How to develop Osing language to finally to existence in the art music Koplo?

Keywords: language, Osing, Banyuwangi, Java

\section{PENDAHULUAN}

Di Era Revolusi Industri 4.0 perkembangan seni digital terus mengalami perubahan terutama pada musik. Bagaimana suatu musik dapat disajikan dengan terus melakukan pemodifikasian sehingga semakin dinikmati oleh para penggemarnya. Terlebih, ditambahkannya sound effect atau effect suara pada suatu musik dengan menggunakan pendekatan teknologi audio bass dan teknik perekaman suara yang akan menghasilkan efek suara yang jernih. Seiring dengan banyak berdirinya studiostudio musik para pengusaha studio musik tersebut berlomba-lomba menghasilkan suara yang jernih dari proses rekaman yang dilakukan oleh para musisi.

Musik memiliki banyak jenis atau genre yang berkembang pada Abad 20-an. Perkembangan tersebut didasarkan atas perkembangan selera yang dimiliki oleh masyarakat dan juga variasi-variasi yang berkembang dihasilkan oleh musik. Tak terkecuali musik koplo yang berkembang dari variasi musik dangdut melayu juga menggambarkan kasta sosial karena pada mulanya musik koplo lahir dari kalangan masyarakat wong cilik. Keberadaan musik koplo kini sudah menjadi selera nasional artinya seluruh kalangan menikmati musik koplo tidak hanya dari kalangan bawah. Musik koplo kian merubah stigma buruk masyarakat terhadap koplo yang mulanya terkenal dengan unsur-unsur erotis dan cenderung memiliki makna seksualitas pada lagu-lagu yang dibawakan menjadi musik yang bertemakan tentang kehidupan anak muda. Sehingga anak muda menyebut istilah musik koplo sebagai 'cendol dawet'. Istilah tersebut karena musik koplo memiliki khas terutama pada pola kendangan yang dihasilkan sehingga musik koplo dianggap musik yang memberikan kesenangan bagi pendengar dikalangan anak muda.

Musik Koplo lahir di Jawa Timur sehingga kebanyakan dari Musik Koplo 
menggunakan Bahasa Jawa dengan dialek khas Jawa Timuran. Akan tetapi Musik Koplo juga menggunakan beberapa bahasa diluar Bahasa Jawa yakni Bahasa Madura dan Bahasa Using. Kedua bahasa tersebut merupakan bahasa daerah dan masyarakat menciptakan karya musik koplo namun dengan bahasa setempat tidak harus menggunakan bahasa Jawa sehingga dapat dimengerti, serta disesuaikan dengan budaya setempat. Musik Koplo merupakan pemodifikasian dari musik Dangdut Melayu yang berkembang pada era 1980-1990 ketika Rhoma Irama memperkenalkan jenis aliran music tersebut kepada kalangan masyarakat sehingga bisa diterima sangat luas. Kemudian di tahun 1990-2000 lahirlah musik Campur Sari sebagai bentuk lokalitas terhadap perkembangan musik dangdut modern. Musik Koplo dibawakan dan diperkenalkan oleh beberapa tokoh diantaranya Didi Kempot, Manthous, dan sebagainya. Musik Campur Sari merupakan jenis musik dengan menggabungkan unsur pop, dangdut, dan keroncong pada setiap alunan nadanya. Musik Campur Sari umumnya berkembang di Jawa Tengah dan Yogyakarta serta bertemakan tentang percintaan. Sedangkan musik koplo merupakan jenis musik bersamaan dengan munculnya Campur Sari. Biasanya yang menjadi perbedaan antara Musik Koplo dengan Musik Campursari terletak pada sisi penyanyinya. Jika musik Campur Sari lahir dari beberapa kelompok tembang Jawa yang kemudian melakukan teknik perekaman di studio-studio musik, sedangkan musik koplo lahir dari panggung ke panggung dan berangkat dari kondisi sosial masyarakat serta bertemakan dengan kehidupan sosial yang ada. Musik Koplo berkembang di Jawa Timur sehingga jika dilihat dari perbedaan dialek baik Musik Campursari maupun Musik Koplo sedikit berbeda satu dengan lainnya. Perbedaan ritme diantara keduanya pun berbeda Musik Campursari diidentikkan dengan teknik langgam, yakni dengan menggunakan ayunan baik suara vocal maupun nada yang dipermainkan, sedangkan koplo diidentikan dengan ritme suara kendang dengan tempo yang cenderung cepat sehingga juga menjadi pembeda antara Musik Koplo dengan Dangdut Modern atau Melayu. Meskipun keduanya memiliki kesamaan yakni sama-sama menggunakan Bahasa 
Jawa sebagai pola komunikasi pada tiap lirik yang digunakan. Saat ini musik koplo menjadi salah satu jenis musik dengan mengedepankan sisi lokalitas terutama pada penggunaan bahasa daerah, salah satunya yakni Bahasa Osing sebagai kelompok bahasa tersendiri di wilayah Jawa Timur selain Bahasa Madura. Secara perbedaan antara Bahasa Osing dengan Bahasa Jawa pada umumnya memiliki kesamaan namun terdapat beberapa kosakata yang berbeda sehingga menjadikan Bahasa Osing sebagai bahasa tersendiri di luar dari Bahasa Jawa. Fokus pada penelitian ini yakni pada penggunaan Bahasa Osing sebagai identitas kelokalan Budaya Banyuwangi melalui musik koplo sebagai bentuk upaya pelestarian budaya yang dikemas dengan pendekatan sosio-kultural.

\section{METODE PENELITIAN}

Penulis menggunakan studi literatur sebagai bentuk penulisan dengan menggunakan sumber atau referensi yang berasal dari arsip, internet, skripsi baik berbentuk digital atau berbentuk fisik dan buku. Pendekatan penulisan menggunakan pendekatan deskritif analisis.

Penulis juga menggunakan pendekatan metode penulisan sejarah yakni dimulai dari heuristik, kritik, interpretasi, dan historiografi. Heuristik (Ismaun, dkk. 2006, hlm. 20) adalah kegiatan yang berkaitan dengan proses pencarian dan pengumpulan sumber sejarah serta penggunaan metode studi konten isi yakni dengan menggunakan pendekatan studi literatur dari beberapa sumber dengan mengkaji beberapa temuan berupa pengumpulan buku-buku sebagai sumber referensi sekaligus pembanding sumber pada pembahasan ini. Dengan kata lain, metode penelitian sejarah adalah instrumen untuk merekonstruksi peristiwa sejarah (sejarah sebagai aktualitas masa lalu) ke dalam sejarah sebagai cerita (sejarah sebagaimana ditulis). Dalam lingkup Ilmu Sejarah, metode penelitian ini disebut metode historis. 
P-ISSN 2580 - 7781

E-ISSN 2615 - 3238

\section{HASIL \& PEMBAHASAN PENELITIAN}

A. Sejarah Perkembangan Musik Koplo

Musik Koplo berkembang pada awal 1990, perkembangan Musik Koplo diawali dari wilayah Jawa Timur. Musik Koplo pertama kali diperkenalkan oleh Naylan (1994-1995) seorang musisi keliling dari Kampung Dukuh Kupang Surabaya. Penggunaan alat musik pada musik koplo juga membaur dengan jenis alat musik lainnya seperti unsur Barat dan Islam. Hal tersebut dengan adanya penggunaan alat musik keyboard, gitar, drum sebagai unsur alat musik Barat sedangkan alat musik unsur lokal seperti penggunaan Rebana dan Tamborin menjadi perpaduaan pada instrument alat musik koplo. Disisi lain juga adanya penggabungan unsur kelokalaan pada alat musik Koplo seperti suling dan kendang menjadi alat instrument utama pada musik koplo.

Musik Koplo pada mulanya hanya dinikmati oleh kalangan masyarakat bawah karena dianggap sebagai jenis musik yang merakyat juga penggunaan lirik yang menggambarkan kehidupan sehari-hari. Sehingga musik Koplo sejak mulanya sudah dapat diterima oleh masyarakat. Mengenai alunan nada pada Musik Koplo sangat berbeda halnya dengan lagu dangdut Rhoma Irama. Kebanyakan lagu dari Rhoma Irama bernadakan slow akan tetapi Musik Koplo memiliki alunan nada yang cenderung cepat.

Kemunculan berbagai O.M (Orkes Musik seperti O.M Monata dan O.M Adella membawa warna musik bagi perkembangan musik koplo di Indonesia. Orkes Musik Monata didirikan oleh H. Gatot dan bermarkaskan di Sidoarjo Jawa Timur pada tahun 1985 (Susanti, 2019, hlm. 3) . Salah satu ciri dari Orkes Musik Monata adalah orkes musik yang berhasil disesuaikan dengan berbagai jenis musik atau genre yang dibawakan ketika tampil. Jenis Musik yang dibawakan berupa Raggae, Pop, Rock, hingga RnB. Kemudian, Orkes Musik Adella didirikan oleh H. Totok pada tahun 2008 yang bermarkaskan di Tuban Jawa Timur. Perbedaan dengan Orkes Musik Monata terletak pada genre lagu yang dibawakan. Orkes Musik Adella lebih banyak 
mengaransemen lagu-lagu dangdut klasik menjadi lagu Koplo. Konsistensi yang dilakukan oleh grup musik O.M Adella membuat menjadikannya ciri khas yang berbeda dengan Orkes Musik lainnya. Kemudian munculnya orkes-orkes musik lainnya seperti O.M Samudra Record, New Pallapa, Sonata, Sera, Pantura dan lainnya.

Mengenai penampilan pada Musik Koplo pada permulaan tahun 2000-2010 dianggap oleh masyarakat sebagai penampilan musik yang jauh dari nilai dan norma. Pada mulanya banyak penyanyi musik koplo yang terkesan vulgar dengan menonjolkan bagian-bagian tubuh yang seharusnya tidak dipertontonkan ditambah dengan adegan saweran sehingga membuat skeptis terhadap keberadaan musik koplo. Akan tetapi perkembangan musik koplo sudah mulai dilirik oleh kalangan masyarakat luas. Terlebih dengan pengunaan sound system, perekaman video, teknik visual, dan lighting sehingga dalam perkembangannya musik koplo sudah mulai dilirik oleh masyarakat kalangan atas (Raditya, 2013, hlm. 4).

B. Selayang Pandang Bahasa Using

Bahasa Using merupakan salah satu bahasa daerah di Banyuwangi dan menjadi ciri khas dari Kabupaten Banyuwangi. Dalam perkembangannya istilah "Using" memiliki arti "Tidak" karena memiliki makna bahwa Bahasa Using bukanlah merupakan dialek Bahasa Jawa. Bukan hanya dilihat dari dialek kebahasaan akan tetapi juga perbedaan kebudayaan dengan masyarakat Jawa. Pada tahun 1114 M di wilayah kekuasaan Mataram Kuno diperkenalkannya istilah Kebudayaan Jawa Baru. Masyarakat Using saat itu menganggap bahwa antara Mataram dengan Using merupakan dua kebudayaan yang berbeda. Hal tersebut diperkuat oleh pernyataan Lekkerkerker seorang ahli Sejarawan Belanda tentang sejarah awal mula Bahasa pada sebuah buku tentang Sejarah Ujung Jawa Timur dengan judul asli Blambangan Gids (1923) (dalam Moriyama, M \& Budiman, M. 2010. Hlm. 231): 
"...dia memberi deskripsi mengenai "mereka yang disebut 'orang Using' [de z.g.n. 'Oesingers'] (dari 'using', 'sing', kata pribumi sebenarnya bahasa Bali-untuk 'tidak')" (Leld(erkerker 1923:1031). Lekkerkerker juga mencatat bahwa "kepribadian, bahasa, dan adat orang Using sangat berbeda dari orang Jawa lainnya" (1923:1031).',

\begin{tabular}{|c|}
\hline $\begin{array}{c}\text { V E R S L A G V A N } \underset{\text { VAN HET }}{\text { H E T C O N G R E S }} \\
\text { JAVA INSTITUUT } \\
\text { GEHOUDEN TE SOERABAIA } 23-27 \text { SEPTEMBER } 1926\end{array}$ \\
\hline $\begin{array}{l}\text { Vervolgens is het woord aan den heer Joh. Scholte, tot het houden van } \\
\text { zijn voordracht over: } \\
\text { GANDROENG VAN BANJOEWANGI }\end{array}$ \\
\hline $\begin{array}{l}\text { De naam O esingers is deze Oos- } \\
\text { telijkste Javanengroep gegeven door de } \\
\text { immigranten naar aanleiding van het } \\
\text { ontkenningswoord ,oesing" of ,sing", } \\
\text { dat ,niet" of "neen" beteekent. } \\
\text { Zelf noemen ze zich ,echte Javanen". } \\
\text { Het best zijn ze aan te duiden met } \\
\text { Bla mbangers. }\end{array}$ \\
\hline
\end{tabular}

(Penjelasan asal usul Bahasa Using dari Joh. Scholte dalam sebuah paper yang berjudul Gandroeng Van Banjoewangi Sumber: Leidenuniv.nl)

Namun ada juga yang menyebutkan bahwa istilah 'Using" merujuk kepada kelompok masyarakat Jawa Kulonan atau masyarakat Jawa bagian barat yang bermigrsi kearah Wetanan atau Timur. Mereka bermigrasi dan bertempat tinggal disisa-sisa Kerajaan Blambangan yang beragama Hindu. Beberapa literatur lainnya yang menyebutknan bahwa orang Using merupakan para migran yang dipekerjakan oleh VOC mengingat wilayah Banyuwangi saat itu terkenal dengan hasil pertanian terutama padi dan jagung. Pada tahun 1970 Bupati Banyuwangi saat itu Soetirsno menyebutkan bahwa Bahasa Osing masih disebut sebagai dialek 'Jawa Osing'. Jika dilihat dari kosakata sekilas antara Bahasa Osing dengan Bahasa Jawa memiliki kesamaan dan sulit untuk dibedakan perbandingan kosakata dengan bahasa Jawa sangat sejajar secara genealogi bahasa karena keduanya merupakan perkembangan dari bahasa Jawa Kuno. Meskipun demikian Masyarakat Using beserta Bahasa Using 
menjadi salah satu entitas tersendiri sekaligus menjadikan ciri khas dari masyakat Using. Seiring dengan perkembangan zaman Bahasa Using terus melakukan upaya transformasi bahasa dengan memperkenalkan Bahasa Using baik melalui komunitas adat seperti pada masyarakat Desa Osing Kemiren hingga melalui musik salah satunya koplo sebagai bentuk upaya pelestarian dari penggunaan Bahasa Using.

C. Karakteristik Musik Koplo

Musik koplo memiliki ciri dan karakteristik diantaranya pola kendangan, adanya instrument suling sebagai pelengkap dalan permainan koplo, tempo yang cenderung cepat sebagaimana dikutip dari Denis Setiaji (Setiaji, 2017, hlm. 26-27) yang mengatakan:

\section{Tabuhan Kendang Musik Koplo}

Pada musik koplo tabuhan kendang sangat variatif hal tersebut hampir pada setiap lagu mulai dari awal lagu hingga akhir lagu tabuhan kendang pada musik sangat disesuaikan juga terus dilakuan secara continue hingga dalam suatu lagu menjelang penutupan.

2. Adanya penggunaan suling pada instrument Musik Koplo

Penggunaan suling terutama suling bamboo menjadi instrument yang wajib Musik Koplo dikarenakan alat musik yang merupakan alat musik dari daerah Jawa Barat kemudian dijadikan sebagai alat musik koplo sehingga menghasilkan alunan khas pada musik koplo.

3. Tempo yang lebih cepat

Pada musik koplo tabuhan kendang cenderung memiliki tempo yang sangat cepat. Berbeda halnya dengan tabuhan kendang pada musik dangdut klasik yang cenderung santai pada ritme tertentu sehingga tempo kendang pada musik koplo menimbulkan kesan yang enerjik pada musik koplo.

Ketiga karakteristik tersebut merupakan ciri khas yang sebenarnya sangat terpengaruh dari dua kebudayaan yang berbeda yakni Kebudayaan India dengan Kebudayaan Melayu. Pada Kebudayaan India disesuaikan dengan alunan nada yang 
P-ISSN 2580 - 7781

E-ISSN $2615-3238$

dihasilkan pada Musik Koplo sedangkan Pengaruh Kebudayaan Melayu ditekankan pada penggunaan syair baik diterapkan khususnya Musik Koplo.

D. Kehadiran 'Demy Banyuwangi'” Sebagai Awal Ketenaran Lagu Banyuwangen

Dewasa ini perkembangan musik daerah terutama musik koplo dari Banyuwangi sangat pesat. Perkembangan tersebut ditandai dengan hadirnya artis-artis lokal dengan lagunya yang laris di pasaran. Salah satu artis berbakat dari Banyuwangi adalah Demy banyak Masyarakat Banyuwangi atau masyarakat luar Banyuwangi khususnya menyebutnya sebagai 'Demy Banyuwangi'” yang merupakan musisi yang selalu membawakan musik bergenre Koplo. Umumnya Ketenaran lagu Banyuwangen terkenal hingga luar daerah Banyuwangi. Bahkan, lagu Banyuwangen terkenal sampai luar Jawa karena musiknya yang easy listening atau lagu yang liriknya ringan dan indah didengar oleh semua orang. Lagu Using yang berasal dari daerah Banyuwangi terdiri dari beberapa genre antara lain, musik etnik, disco, kendang kempul, remix, pop, dan rock dangdut-koplo (Ya'yunita. 2015. Hln. 17).

Karya dari Demy yang terkenal adalah "Kanggo Riko" lagu tersebut menceritakan seseorang memiliki rasa cinta terhadap seseorang yang dicintainya dan melakukan apa saja demi mengungkapkan rasa percintaanya. Lagu Kanggo Riko kemudian terkenal bahkan di luar Jawa banyak para musisi kemudian mengcover ulang atau mengaransemen ulang menjadi beberapa bahasa daerah agar dapat dimengerti oleh masyarakat luas. Kemudian lagu tersebut diaransemen ulang oleh musisi koplo terkenal seperti Nella Kharisma dan Via Vallen. Bukan hanya itu saja lagu Kanggo Riko terdapat beberapa aplikasi hiburan digital seperti TikTok, Spotify, dan Youtube dan beberapa aplikasi lainnya. Fenomena anak muda yang kemudian melakukan cover atau rekaan ulang lagu Kanggo Riko baik dalam bentuk pop, rnb, hingga keroncong menjadikan lagu Kanggo Riko menjadi selera nasional.

Tema yang terdapat pada lirik lagu Demy yakni kesetiaan, kekecewaan, keyakinan, kehampaan dan kesungguhan cinta. Dari aspek psikologis kebanyakan 
lagu-lagu yang dibawakan oleh Demy selalu bertemakan tentang perjuangan seseorang dalam mencapai cintanya. Namun beberapa lagu Demy juga menceritakan tentang kepergian seseorang salah satunya lagu 'Tutupe Wirang'. Penggambaran pada lagu tersebut digambarkan oleh Demy sebagai rasa duka dan kepedihan hati seseorang ketika telah ditinggal oleh seorang yang dirasa mencintainya. Sama halnya dengan lagu 'Kanggo Riko', lagu 'Tutupe Wirang'” banyak dinikmati dan direka ulang oleh baik musisi terkenal maupun anak muda (Azhari. 2017, hlm. 15.).

Kehadiran Demy juga menjadi awal kebangkitan bagi lagu-lagu Koplo Banyuwangen mengingat nama Demy sudah mulai dikenal oleh Masyakarat Banyuwangi sepanjang tahun 2012-2015. Berkat ketenarannya Demy kemudian banyak melakukan berbagai penampilan bahkan pernah tampil oleh salah satu stasiun televisi swasta untuk tampil di Jakarta pada tahun 2017 lalu. Demy kemudian menjadi inspirasi bagi Masyarakat Banyuwangi khususnya Suku Osing dalam selalu terus mengembangkan Bahasa Using.

E. Kemunculan Penyanyi Lain Semakin Mempertahankan Musik Koplo Using

Sebelum kemunculan beberapa musisi lain yang memperkenalkan Lagu Banyuwangen pada tahun 2000-2004 muncul seorang musisi senior asal Banyuwangi yakni Catur Arum. Catur Arum dikenal oleh Masyarakat Banyuwangi karena pertama kali musisi yang mempekenalkan pakem music asal Banyuwangi. Namanya pertama kali terkenal setelah membawakan sebuah lagu yang berjudul 'Usum LayangLayang”. Syair-syair pada lagu-lagu Catur Arum cukup kental dengan dialek dan idiom-idiom Using. Sebagaimana umumnya Bahasa Using yang dikenal simbolis dan bertingkat, syair lagu Usum Layangan itu juga tidak sekadar menggambarkan tentang serunya sebuah permainan layang-layang. Beberapa karya dari Catur Arum diantaranya Sing Duwe Isin, Angen-angen, Bantalan Dadane, dan sebagainya.

Kemudian tahun 2015 hingga saat ini munculnya Nella Kharisma dalam membawakan lagu-lagu Koplo Banyuwangi. Nella Kharisma merupakan salah satu penyanyi dangdut asal Kediri Jawa Timur sejak usia muda Nella Kharisma sangat 
akrab dengan musik diawali dengan "nyinden". Faktor orang tua juga membentuk pribadi Nella Kharisma sebagai penyanyi terkenal musik koplo. Kebanyakan lagulagu Nella Kharisma baik berbahasa Jawa maupun berbahasa Using memilik makna denotatif dan konotatif yang merupakan makna ungkapan perasaan seseorang dan bertemakan tentang percintaan. Seperti contoh pada lagu Using "Bisane Nyawang". Sebenarnya lagu Bisane Nyawang pertama kali diciptakan dan dinyanyikan oleh Vita Alvia (seorang penyanyi asal Banyuwangi) dan Ali sebagai pencipta lagu tersebut. Kemudian lagu tersebut dinyanyikan kembali oleh Nella Kharisma dengan aransemen Koplo. Adapun penggalan lirik pada lagu Bisane Nyanwang:

bisane mung nyawang, sing biso ndampingi

bisane mung ngangen, sing biso nduweni

riko hang sun sayang, wis ono hang ngudang

riko hang sun eman, wis duwen wong liyan

getun rasane ati sing biso nduweni

riko hang sun demeni, riko hang sun welasi

wis ono hang ngrumati

Jika dari penggalan lirik tersebut terdapat dua makna yakni denotative dan konotatif pada lirik tersebut terutama kata "getun" dan kata "nyawang". Pertama kata nyawang Kata nyawang yang bermakna ,melihate pada data di atas mengacu pada makna yang tidak sebenarnya. Dalam kamus Bahasa Using (2002. Hlm. 367) kata nyawang adalah lihat; pandang; memandang. Kata Nyawang termasuk kata denotative. Kedua kata "getun" yang bermakna menyesal pada data di atas mengacu pada makna yang sebenarnya. Dalam kamus Bahasa Osing (2002. Hlm. 139) kata getun adalah kecewa dan menyesal. Kata getun pada lirik lagu di atas mengacu pada makna yang sebenarnya yaitu menyesal. Artinya, seseorang merasa menyesal mengenal seorang perempuan yang membuat ia sakit hati. Kata getun pada data di atas mengacu pada makna denotatif, karena kata tersebut tidak mengandung makna yang lain. Artinya, tidak ada makna yang dirancukan dalam kata getun. 
Disisi lain, bukan hanya saja Nella Kharisma akan tetapi para musisi lokal juga ikut memperkenalkan Musik Koplo berbahasa Using. Karena tanpa adanya campur tangan musisi lokal Bahasa Using tidak akan dinikmati kembali melalui Musik Koplo. Kehadiran Musik Koplo terutama dalam berbahasa Using secara disengaja ataupun tidak dapat diperkenalkan kepada semua kalangan bahwa kehadiran musik koplo berbahasa daerah semakin berkembang. Sehingga dapat mempertahankan eksistensi dari Bahasa Using sebagai Bahasa Asli Penduduk Banyuwangi. Nella dan Demy merupakan kedua sosok yang membawa Musik Koplo Using menjadi suatu fenomena lagu musik koplo pada tingkatan nasional dan sangat disenangi oleh anak muda khususnya ditengah banyaknya budaya asing yang masuk didunia Permusikan Indonesia khususnya Budaya K-Pop sehingga kehadiran kedua penyanyi dangdut tersebut dapat menyaingi pengaruh budaya K-Pop tersebut.

\section{KESIMPULAN}

Perkembangan Musik Koplo khususnya dalam Bahasa Using telah mengangkat nama 'Banyuwangi'" dan juga "'Suku Osing"' semakin dikenal oleh masyarakat luas yang diawali dengan lahirnya musisi yang bernama Demy dengan judul lagu "Kanggo Riko" telah menyulap musik koplo menjadi selera nasional yang dinikmati oleh berbagai kalangan. Penggunaan bahasa yang mudah dimengerti dan diikuti merupakan salah satu mengapa musik koplo khususnya Bahasa Using sangat digemari oleh masyarakat. Ditambah, lirik-lirik pada lagu koplo menggamharkan kehidupan sehari-hari maka dapat dikatakan kecenderungan masyarakat akan musik koplo sangat erat dengan kehidupan saat ini. Salah satu yang menjadi daya tarik pada Bahasa Using apabila dijadikan dalam bentuk lagu yakni penggunaan bahasa yang sangat sederhana sehingga dapat dimengerti bagi para pendengarnya terutama di luar dari Masyarakat Osing atau Banyuwangi itu sendiri. Bahasa Osing saat ini seakan memiliki daya tarik tersendiri sehingga banyak para musisi baik musisi Banyuwangi 
maupun non Banyuwangi sama-sama untuk melestarikan Bahasa Osing sebagai bentuk kelokalan khas dari Budaya Osing Banyuwangi.

Feedback, khususnya wilayah Banyuwangi menjadi salah satu pusat kebudayaan bukan hanya pusat pariwisata namun sektor kebudayaan dan wisata kesenian terus dikembangkan oleh pemerintah setempat guna menjadikan wilayah Banyuwangi menjadi salah satu destinasi wisata budaya terbaik kedepan salah satu contoh melalui Desa Adat Kemiren sebagai desa wisata. Disisi lain sebagai upaya untuk melestarikan Bahasa Using sehingga dapat dikenal oleh masyarakat keberadaanya.

\section{DAFTAR PUSTAKA}

Ali, Hasan. (2002). Kamus Bahasa Using. Banyuwangi: Dewan Kesenian Blambangan

Alwi, Hasan. Dkk. (1988). Tata Bahasa Baku Bahasa Indonesia edisi ke 3 Jakarta: Balai Pustaka

Arsip Joh. Scholte Gandroeng van Banjoewangi Diakses https://openaccess.leidenuniv.nl/bitstream/handle/1887/15213/Arps+2 010.pdf . 06 Januari 2020. The Hague : KITLV Nederland.

Azhari, Yahya. (2017). Tinjauan Psikologis Lirik Lagu Demy. [Online]. UPT Universitas PGRI Kediri

Ismaun, dkk (2010). Metodologi sejarah. Bandung: Asosiasi Pendidikan Sejarah

Jasi, M. (2000). Interaksi Simbolik. PT. Raja Grafindo: Jakarta

Latifa. (2015). Diksi dan gaya bahasa pada lirik lagu Berbahasa Using.[Skripsi]. [Online]. UPT Skripsi Universitas Negeri Jember

Moriyama, M \& Budiman, M. (2010). Geliat Bahasa Selaras Zaman: perubahan bahasa-bahasa di Indonesia pasca Orde Baru. Jakarta: Kepustakaan Populer Gramedia

Raditya, M. H. B. (2013). Dangdut Koplo : Selera Lokal Menjadi Selera Nasional. Jurnal Seni Musik, 2(2), 1-6.

Rifkyanto, Azis. (2012). Analisis bentuk lagu Red Pashima karya kelompok kwartet Cello Fontcello. [Skripsi]. Universitas Negeri Yogyakarta.

Setiaji, D. (2017). Tinjauan Karakteristik Dangdut Koplo Sebagai Perkembangan Genre Musik Dangdut. Handep: Jurnal Sejarah Dan Budaya, 1(1), 19-34. https://doi.org/10.33652/handep.v1i1.13

Susanti, F. D. W. I. (2019). Perkembangan musik dangdut koplo jawa timur tahun 2003 - 2017. 7(3) Jurnal Pendidikan Sejarah Universitas Negeri Surabaya, $1-8$. 


\section{Volume 4 , Nomor 1, Juli 2020}

P-ISSN 2580 - 7781

E-ISSN $2615-3238$

Smarapradhipa, Galih. (2005). Bertutur Dengan Tulisan. [Online]. diakses http://www.Rayakultura.com 08 Januari 2020

Setiawan. (2006). Bahasa dalam komunikasi. Jakarta: Alfabeta

Tanpa Penulis. (1990). Kamus Besar Bahasa Indonesia. Jakarta: Balai Pustaka 